\title{
Solving the transverse bending problem of thin elastic orthotropic plates with form factor interpolation method
}

\author{
V. I. Korobko" ${ }^{1}$ A. V. Korobko ${ }^{1}$, S. Y. Savin ${ }^{1 *}$, A. A. Chernyaev ${ }^{1}$ \\ ${ }^{1}$ Orel State University, 95 Komsomolskaya Street, 302026, Orel, Russia, \\ e-mail: suwin@yandex.ru \\ *corresponding author
}

\begin{abstract}
The article deals with the transverse bending problem of thin elastic orthotropic plates with combined boundary conditions. The form factor interpolation method is used for deformation calculations. Analytical expressions of maximum deflection surfaces are obtained. It is proposed to use these expressions as the reference solutions. The example of the solution to the problem of transverse bending plate in the form of a parallelogram is given.
\end{abstract}

Keywords: orthotropic plates, transverse bending, form factor, ratio of flexural rigidities, combined boundary conditions, maximal deflection, form factor interpolation method

\section{Introduction}

Thin orthotropic plates are widely used as elements of the roof structures or the floor of buildings, as well as thin-walled girders with ribs. As it is shown by Ambartsumyan (1991), the relation between flexural and shear rigidities often allows to perform deformation calculation for orthotropic plates in a classical form, i.e. using the Kirchhoff - Love plate theory.

The assignment of plate strain function (or stress function), which satisfies all boundary conditions, is one of the main difficulties, when it is necessary to calculate deflections or internal forces. In practice, the exact solution can be obtained for a limited classes of problems, in particular, for rectangular plates, which are simply supported on two opposite sides and arbitrary fixed on both other sides as well as for elliptic plates, which are clamped all over the boundaries. Usually, it is necessary to use approximate analytical or numerical methods. Numerical methods are leaders today due to its versatility, sufficient accuracy and realization within software complexes for personal computers. However, the numerical methods have significant drawback, which appears, when it is neccessary to find optimal parameters of the cross section or midplane shape of the plate, because this procedure reduces to sequential calculation until the elected parameter takes the optimum value. In many cases, it takes a long time or gives a local extremum of parameter. That is why approximate analytical methods should continue to develop in parallel with numerical methods.

In the paper (Mbakogu, Pavlovic 2000) authors use the Galerkin variation method to obtain approximations for infinite series representing the deflection function for the orthotropic rectangular plate, clamped on the contour. Rui Li, Yang Zhong, Bin Tian, Yuemei Liu (2009) solve the same problem. They use the method of final integrated conversions, which allows to 
avoid a preliminary definition of deflection function. In the paper (Huu-Tai Thai, Seung-Eock Kim 2012), authors propose the analytical solution, based on the specified theory, for deformations and tension of the orthotropic plates. Authors consider the case, when a rectangular plate is simply supported on the two opposite sides and has arbitrary boundary conditions on the both other sides. Kurpa L., Rvachev V. and Ventsel E. (2003) offer to use the R-functions method to solve the free vibrations problem for thin orthotropic plates of arbitrary form. The results of the article can be extended to the transverse bending problem, because free vibrations and transverse bending are described by the similar differential equations. Bao G., Jiang W., Roberts J. (1997) compare various analytical and numerical solutions for thin orthotropic plates, which have various combination of simple supporting and clamping along the contour. In the present paper we show development of the form factor interpolation method (FFIM), proposed by Korobko A. (1999). This approximate method is the logical evolution of isometric method, which was stated in the papers of Polya G. and Szego G. (1951), Korobko V. (1997), Lowe P.G. (1984), Lowe P., Allen J., Collins I. (1994) and others.

\section{Two-dimensional region form factor}

Two-dimensional region form factor is the loop integral

$$
K_{f a}=\oint_{L} \frac{d s}{h},
$$

where $d s$ is an elementary part of a two-dimensional region contour; $h$ represents perpendicular from an arbitrary point, called pole, on contour section $d s$. At any convex region unique point " $a$ " should exist, for which form factor value is minimal (Korobko 1997)

$$
\min K_{f a}=K_{f} .
$$

The monograph (Korobko 1999) contains form factor formulas for convex regions of different outlines as well as a detailed investigation of its isoperimetric properties.

\section{Form factor interpolation method}

Polya G. and Szego G. (1951) show that geometrical torsional rigidity of beam cross section $I_{k}$ can be written in isoperimetric form. Using results, that are presented in (Korobko 1997) for torsion of elastic prismatic beams, authors obtained the diagram of relationship between squared normalized geometrical torsion rigidity of section $i_{k}^{2}$ and the inverse form factor value $1 / K_{f}$, as can be seen from Fig.1. The normalized geometrical torsion rigidity of section is determined by the formula:

$$
i_{k}=I_{k} / A^{2}
$$

where $A$ is area of cross section.

Similarly, using the data from (Korobko 1997) for transverse bending of elastic isotropic plates, we obtained the diagram of maximal deflection of fully clamped plates $1000 W_{0}$ from the inverse form factor value $1 / K_{f}$, as can be seen from Fig.2. The comparison of these diagrams shows their high similarity. At the same time, as can be seen from Fig.1 and Fig.2, all values of $i_{k}^{2}$ and $W_{0}$ are restricted on the both sides. The lower boundary is formed by the values $i_{k}^{2}$ and $W_{0}$ of elliptic plates (curves III), and top boundary is formed by the values $i_{k}^{2}$ and $W_{0}$ of plates in the forms of regular polygons (curves I) and isosceles triangle (curves II). Curves IV in the figures 
correspond to the rectangular cross-sections, as can be seen from Fig.1, and rectangular plates, as can be seen from Fig.2. The similar result corresponds to the case of simply supported plates (Korobko 1997).

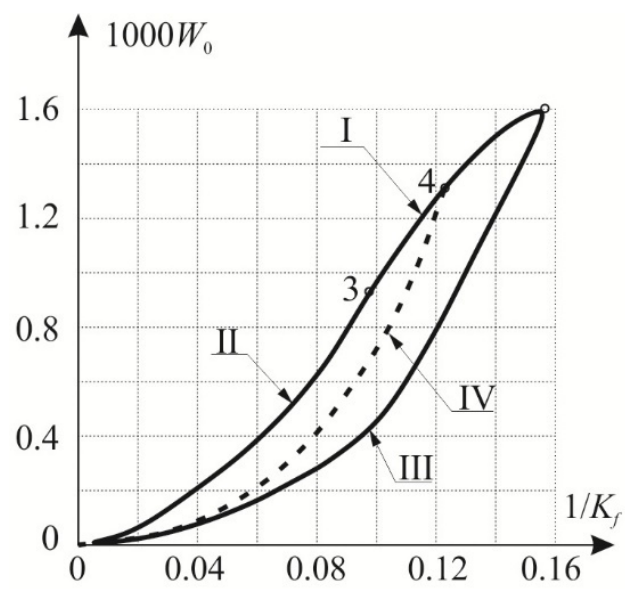

Fig. 1. Diagram $i_{k}^{2}-1 / K_{f}$ for torsion of elastic prismatic beams

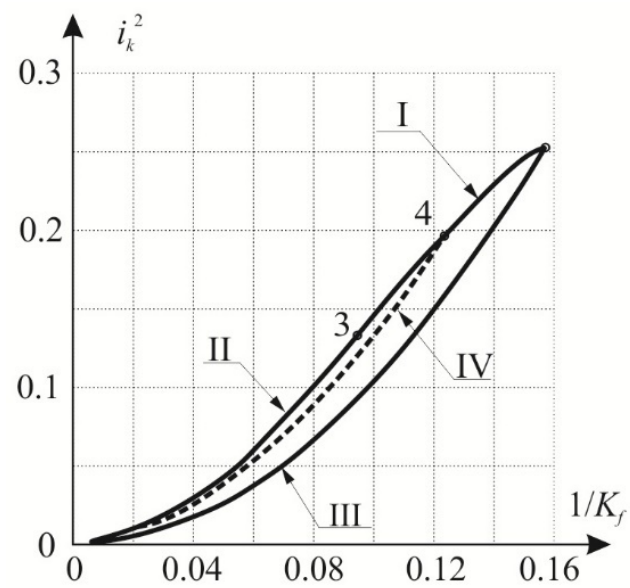

Fig. 2. Diagram $1000 W_{0}-1 / K_{f}$ for transverse bending of clamped isotropic plates form:

The equation of total potential energy of transverse bending $\Pi$ for isotropic plates has the

$$
\Pi=\frac{D}{2} \iint\left\{\left(\nabla^{2} w\right)^{2}+2(1-v)\left[\frac{\partial^{2} w}{\partial x^{2}} \cdot \frac{\partial^{2} w}{\partial y^{2}}+\left(\frac{\partial^{2} w}{\partial x \partial y}\right)\right]\right\} d A-\iint q(x, y) \cdot w d A,
$$

where $w$ is deflection function, $D$ is flexural rigidity, $A$ is median surface area of plate, $q(x, y)$ is loading.

However, one of the terms from the formula (2) takes the value of zero for the case of homogenous boundary conditions: 


$$
\iint\left[\frac{\partial^{2} w}{\partial x^{2}} \cdot \frac{\partial^{2} w}{\partial y^{2}}+\left(\frac{\partial^{2} w}{\partial x \partial y}\right)\right] d A=0 .
$$

We present the deflection function $w$ in the form:

$$
w=w(x, y)=W_{0} \cdot f(x, y)
$$

where $f(x, y)$ is dimensionless function, which characterizes the curved midplane of the plate and takes values from 0 to 1 .

We transform formula (2), according to previous comments:

$$
\Pi=\frac{D \cdot W_{0}^{2}}{2} \iint\left(\nabla^{2} f\right)^{2} d A-W_{0} \iint q(x, y) \cdot f d A .
$$

We carry out the minimization of the expression (3) of total potential energy to find the maximum deflection of the plate:

$$
\frac{\partial \Pi}{\partial D}=D \cdot W_{0} \iint\left(\nabla^{2} f\right)^{2} d A-\iint q(x, y) \cdot f d A=0 .
$$

Hence, for the case of constant loading $q(x, y)=q$, we obtain:

$$
W_{0}=\frac{q \iint f d A}{D \iint\left(\nabla^{2} f\right)^{2} d A} .
$$

The integrals from formula (4) can be written in the form:

$$
\begin{aligned}
& \iint f d A=\int_{0}^{2 \pi} \int_{0}^{r} g(\rho) \frac{1}{r^{2}} t d t d \varphi=\int_{0}^{2 \pi} r^{2} d \varphi \int_{0}^{r} g(\rho) \frac{t}{r} \frac{d t}{r}=2 A \int_{0}^{1} g(\rho) \rho d \rho, \\
& \iint\left(\nabla^{2} f\right)^{2} d A=\int_{0}^{2 \pi r} \int_{0}^{r}\left[g^{\prime \prime} \frac{1}{r^{2}}\left(1+\frac{r^{\prime 2}}{r^{2}}\right)+g^{\prime} \frac{1}{t r}\left(1+2 \frac{r^{\prime 2}}{r^{2}}-\frac{r^{\prime \prime}}{r}\right)\right]^{2} t d t d \varphi=\frac{K_{f}^{2}}{2 A} \Phi_{g},
\end{aligned}
$$

where

$$
\begin{gathered}
K_{f}^{2}=\left[\int_{0}^{2 \pi}\left(1+2 \frac{r^{\prime 2}}{r^{2}}-\frac{r^{\prime \prime}}{r}\right) d \varphi\right]^{2}, \\
\Phi_{g}=\int_{0}^{1}\left(g^{\prime \prime 2} \rho+2 g^{\prime \prime} \cdot g^{\prime}+g^{\prime 2} \rho^{-1}\right) d \rho, \\
\rho=t_{\kappa} / r(\varphi) .
\end{gathered}
$$

Then we obtain maximum deflection, using formulas (4) and (5):

$$
W_{0}=\frac{4 q \cdot A^{2}}{D \cdot K_{f}^{2}} \frac{\int_{0}^{1} g(\rho) \rho d \rho}{\Phi_{g}},
$$


In equations (6) and (7) $\rho$ denotes dimensionless coordinate conforming to contour lines of the deflection surface; $t_{\kappa}$ is polar coordinate of points on the plate's contour; $r(\varphi)$ represents polar function of plate contour; $\varphi$ is polar angle; $g=g(\rho)$ denotes dimensionless functions of deflections in one-parametric form; $A$ is median surface area of plate; $D$ is flexural rigidity; $q$ represents intensity of uniformly distributed load.

We introduce the following notation:

$$
\int_{0}^{1} g(\rho) \rho d \rho /\left(K_{f}^{2} \cdot \Phi_{g}\right)=I .
$$

The function $I$ can be replaced by elementary approximate functions that are close to real functions for the given geometrical transformation. The easiest and most natural transformations are power and linear (regarding to $K_{f}^{2}$ ) approximate functions that are suggested in the monograph (Korobko 1999):

$$
\begin{aligned}
& W_{0}=K_{\mathrm{w}} \cdot K_{f}^{n}, \\
& W_{0}=B+C \cdot K_{f}^{2} .
\end{aligned}
$$

Here $K_{w}, n, B$ and $C$ are unknown parameters, which can be determined from the solutions for basic plates, if the forms of these plates are related with the form of the given plate. The minimum number of basic solutions is two.

Below, the procedure of applying the form factor interpolation method is described. So, it is necessary to determine the value of maximum deflection for the given plate. The form of this plate can be obtained as a result of any geometrical transformation from other plates (basic plates). If integral physical characteristics of basic plates (reference solutions) are known, then desired value $W_{0}$ for given plate can be found interpolating between reference solutions, using the function (8) or (9).

The main positive feature of this method is the possibility to reduce the complicated twodimensional problem, which is described using fourth-order differential equations of elliptic type, to simpler geometrical problem. At the same time, the results of calculations can be visualized in the form of diagram of physical-mechanical parameters and form factor.

Despite the mentioned advantages, the form factor interpolation method has not wide application now. There are few papers of V. Korobko, A. Korobko and their followers (Korobko et al. 2015; Korobko et al. 2016), which represent an application of this method to the transverse bending and free vibration problems for elastic isotropic plates.

The present paper is devoted to the development of the form factor interpolation method for solving the problems of elastic orthotropic plates transverse bending.

\section{Orthotropic plates transverse bending}

The differential equation for transverse bending of orthotropic plate, subjected to the uniform distributed load, has the form:

$$
D_{x} \frac{\partial^{4} w}{\partial x^{4}}+2 H \frac{\partial^{4} w}{\partial x^{2} \partial y^{2}}+D_{y} \frac{\partial^{4} w}{\partial y^{4}}=q,
$$


where $H=D_{1}+2 D_{x y}, \quad D_{1}=D_{x} v_{y}=D_{y} v_{x}$. In these expressions $D_{x}, D_{y}, D_{x y}$ are flexural rigidities of the plate; $v_{x}, v_{y}$ are Poisson's ratios in relevant directions. By dividing left and right parts of the equation (10) by $H$, the following equation is obtained:

$$
\frac{D_{x}}{H} \frac{\partial^{4} w}{\partial x^{4}}+2 \frac{\partial^{4} w}{\partial x^{2} \partial y^{2}}+\frac{D_{y}}{H} \frac{\partial^{4} w}{\partial y^{4}}=\frac{q}{H} .
$$

The approximate solution of this differential equation can be found as function of three parametrs: $K_{f}, D_{x} / H, D_{y} / H$. In this case, we obtain equation for the maximum deflection:

$$
W_{0}=f\left(K_{f} ; D_{x} / H ; D_{y} / H\right) \frac{q A^{2}}{H} .
$$

\section{Constructing the boundary surfaces of deflection for orthotropic plates of the basic form}

It is necessary to obtain the deflection functions for particular classes of region's form (basic forms): isosceles and right-angled triangles, rhombs, rectangles and regular n-gons. Values of integral physical characteristics for basic plates give range boundaries of the maximum deflections for all orthotropic plates with convex contour. We used numerical solution of differential equations by the finite element method to obtain the approximate deflection functions for basic plates (Zienkiewicz, Taylor 2005).

The solution for isosceles triangles has the following form:

$$
f=g_{1}\left(K_{f}\right) \cdot g_{2}\left(D_{x} / H ; D_{y} / H ; \alpha\right),
$$

where $g_{1}$ is a function which depends on the boundary conditions and form of the plate; $g_{2}$ is a function, which depends on the parameters $D_{x} / H, D_{y} / H$ and takes value equal one for acute triangles.

The function $f$ for orthotropic plates in the form of right-angled triangles, rectangles, rhombs and regular polygons takes the following form:

$$
\begin{aligned}
f=a_{1} & +a_{2} \frac{H}{D_{x}}+a_{3} \frac{H}{D_{y}}+a_{4} \frac{H^{2}}{D_{x}^{2}}+a_{5} \frac{H^{2}}{D_{y}^{2}}+a_{6} \frac{H^{2}}{D_{x} D_{y}}+ \\
& +a_{7} \frac{H^{3}}{D_{x}^{3}}+a_{8} \frac{H^{3}}{D_{y}^{3}}+a_{9} \frac{H^{3}}{D_{x} D_{y}^{2}}+a_{10} \frac{H^{3}}{D_{x}^{2} D_{y}} .
\end{aligned}
$$

where $a_{i}=a\left(K_{f}\right)$.

The coefficients $a_{i}$ for rectangular plates are determined by the formula:

$$
a\left(K_{f}\right)=\frac{A+C K_{f}^{m / 2}+E K_{f}^{m}+G K_{f}^{3 m / 2}+I K_{f}^{2 m}}{1+B K_{f}^{m / 2}+D K_{f}^{m}+F K_{f}^{3 m / 2}+H K_{f}^{2 m}},
$$

and the coefficients $a_{i}$ for plates in the form of right-angled triangles, rectangles, rhombs and regular polygons are determined by the formula:

$$
a\left(K_{f}\right)=A+\frac{B}{K_{f}}+\frac{C}{K_{f}^{2}}+\frac{D}{K_{f}^{3}}+\frac{E}{K_{f}^{4}}+
$$




$$
\frac{F}{K_{f}^{5}}+\frac{G}{K_{f}^{6}}+\frac{H}{K_{f}^{7}}+\frac{I}{K_{f}^{8}}+\frac{J}{K_{f}^{9}} .
$$

In the expressions $A \ldots J$ are the coefficients, which are constant for corresponding subclasses of region's form and boundary conditions; $m=1,2,4$.

\section{FFIT application for elastic orthotropic plates' calculation}

The following test example demonstrates the application of the form factor interpolation method for deformation analysis of elastic orthotropic plate. The plywood plate has form of parallelogram, as can be seen from 0 in center. The plate is subjected to the uniform distributed load, having intensity $q=10 \mathrm{kN} / \mathrm{m}^{2}$. Source data are the following: $a=1.5 \mathrm{~m} ; b=1 \mathrm{~m} ; t=0.02$ $\mathrm{m} ; \alpha=45^{\circ} ; K_{f}=12.2565 ; A=1.061 \mathrm{~m}^{2}, E_{x}=7000 \mathrm{MPa} ; E_{y}=5500 \mathrm{MPa} ; G_{x y}=800 \mathrm{MPa} ; v_{x}=$ 0.07. It is required to find the value of maximum deflection for the plate.

Solution. In the first approximation, plywood can be considered an orthotropic material. The given plate can be obtained as a result of affine shift of a rectangular plate into rhombic. As can be seen from Fig.3 the maximum deflection value for the given plate locates between the maximum deflection curves for rectangular and rhombic plates. Parameters of rectangular plate are: $a=1.5 \mathrm{~m} ; b=0.707 \mathrm{~m} ; K_{f 1}=10.371 ; A_{1}=1.061 \mathrm{~m}^{2}$; parameters of rhombic plate are: $a=$ $1.5 \mathrm{~m} ; \alpha=28.1^{\circ} ; K_{f 2}=16.971 ; A_{2}=1.061 \mathrm{~m}^{2}$. Here indexes " 1 " and "2" are related to the parameters of the first and second reference plates. Values of maximum deflection $\left(W_{0}\right)_{1}=1.861$ $\mathrm{mm} ;\left(W_{0}\right)_{2}=1.892 \mathrm{~mm}$ for reference plates can be obtained from expression (14). Substituting these reference solutions in the formula (9), we obtained the value $W_{0}=1.868 \mathrm{~mm}$, which differs about $0.2 \%$ from results $W_{0}=1.865 \mathrm{~mm}$, that was found with the finite element method at continuum-partition into 1000 shell finite elements.

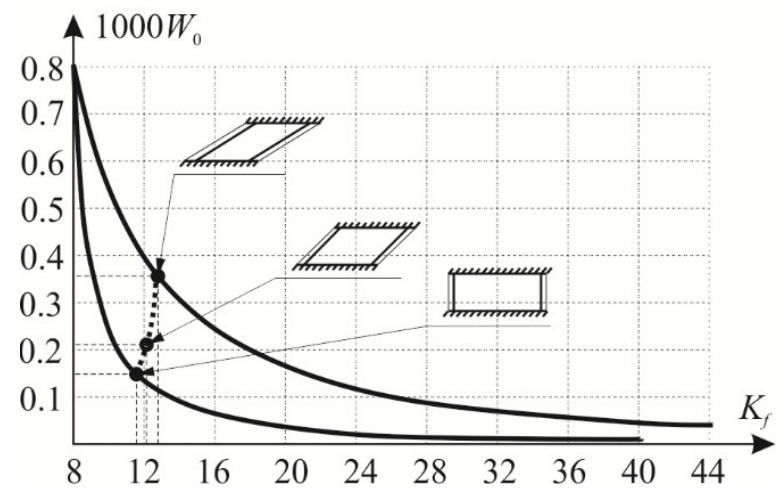

Fig. 3. Diagram of $1000 W_{0}-K_{f}$ for test example

\section{Conclusions}

Summarizing paper results, the following conclusions can be formulated:

1. The form factor interpolation method has been extended to solve transverse bending problems (determination of maximum deflection) of elastic orthotropic plates, subjected to the uniform distributed load. The functions of maximum deflections for the basic shapes of plates (triangles, rectangles, rhombuses, etc.) have been shown. An example 
of application of the form factor interpolation method has been presented. The results have been validated against values obtained by other methods.

2. Due to mathematical similarity of differential equations, which describe transverse bending problems, problems of free vibrations and stability, the proposed method can be extended to solve these problems.

Извод

\title{
Решавање проблема трансверзалног савијања еластичних ортотропних плоча техником интерполације фактора облика
}

\author{
V. I. Korobko' ${ }^{1}$ A. V. Korobko ${ }^{1}$, S. Y. Savin ${ }^{1 *}$, A. A. Chernyaev ${ }^{1}$ \\ ${ }^{1}$ Orel State University, Komsomolskaya 95, 302026, Орел, Русија \\ имејл: suwin@yandex.ru \\ * главни аутор
}

\section{Резиме}

У овом раду се разматра проблем трансверзалног савијања ортотропних плоча са комбинованим граничним условима. Техника интерполације фактора облика је коришћена за срачунавање деформација. Добијени су аналитички изрази за површине максималног угиба. Ови изрази су коришћени при избору референтних решења. Дат је пример решења проблема трансверзалног савијања плоче облика паралелограма.

Кључне речи: ортотропне плоче, трансверзално савијање, фактор облика, однос савојне крутости, комбиновани гранични услови, максимални угиб, метода интерполације фактора облика

\section{References}

Ambartsumyan S (1991). Theory of Anisotropic Plates: Strength, Stability and Vibration, Hemisphere Publishing, New York.

Bao G, Jiang W, Roberts J (1997). Analytic and finite element solutions for bending and buckling of orthotropic rectangular plates. International Journal of Solids and Structures, 14, 1797-1822.

Huu-Tai Thai, Seung-Eock Kim (2012). Analytical solution of a two variable refined plate theory for bending analysis of orthotropic Levy-type plates, International Journal of Mechanical Sciences, 1, 269-276.

Korobko A (1999). Geometricheskoe modelirovanie formy oblasti v dvumernykh zadachakh teorii uprugosti [Geometrical Modeling of Region Form in the Two-Dimensional Problems of Elasticity Theory], ASV Publishing, Moscow (in Russian).

Korobko V (1997). Isoperimetric Method in Structural Mechanics: Theory of the Isoperimetric Method, ASV Publishing, Moscow (in Russian).

Korobko V, Korobko A, Chernyaev A, Savin S (2015). Determination of maximum deflection at cross bending parallelogram plates using conformal radius ratio interpolation technique, Journal of the Serbian Society for Computational Mechanics, 1, 36-45. 
Korobko V, Korobko A, Chernyaev A (2016). Isoperimetric properties of the torsion rigidity of convex sections, Procedia Engineering, 150, 1648-1656.

Kurpa L, Rvachev V, Ventsel E (2003). The R-function method for the free vibration analysis of thin orthotropic plates of arbitrary shape. Journal of Sound and Vibration, 261, 109-122.

Lowe P (1984). Isoperimetric inequalities in structural mechanics. The ninth Australian Conference on the Mechanics of Structures and Materials, University of Sydney, Sydney, 147-151.

Lowe P, Allen J, Collins I (1994). Limit Analysis of Plates and Isoperimetric Inequalities, Philosophical Transactions of the Royal Society A: Physical, Mathematical and Engineering Sciences, 347, 113-137.

Mbakogu F, Pavlović M (2000). Bending of clamped orthotropic rectangular plates: a variational symbolic solution, Computers \& Structures, 2, 117-128.

Polya G, Szego G (1951). Isoperimetric inequalities in mathematical physics, Princeton Univ. Press, Princeton.

Rui Li, Yang Zhong, Bin Tian, Yuemei Liu (2009). On the finite integral transform method for exact bending solutions of fully clamped orthotropic rectangular thin plates, Applied Mathematics Letters, 12, 1821-1827.

Zienkiewicz O, Taylor R (2005). The Finite Element Method for Solid and Structural Mechanics, Elsevier. 